4 Background: Pharmacies are a primary source of healthcare services in low and middle 5 income countries, especially where patient to physician ratio is low. Due to the wide variability 6 in the training of pharmacy workers, inappropriate antibiotic dispensing is common, which

\section{Factors associated with inappropriate dispensing of antibiotics among non-pharmacist}

pharmacy workers

\section{Abstract}

Objectives: This study aims to understand the factors that drive the inappropriate dispensing of antibiotics among pharmacy workers in Bahawalpur, Pakistan.

Methods: In this qualitative study, the data were collected from the pharmacy workers through semi-structured interviews. A two-step sampling procedure, including purposive and convenient sampling techniques, was adopted to recruit the study participants. The sample size was determined by applying the saturation point criteria. All interviews were audio recorded and transcribed verbatim. The data were analysed to draw conclusions using the inductive thematic analysis approach.

Results: A total of 16 in-depth interviews were conducted. Data analysis yielded four themes and 18 subthemes. Under-dispensing and dispensing of antibiotics without need were reported. Lack of knowledge of dispensers, false feeling of being qualified, social acceptance, customer demands, public beliefs, high consultation fees of doctors, expensive diagnostic tests, economic influences and profit maximization were the main factors associated with the inappropriate dispensing of antibiotics.

Conclusions: Multiple pharmacy worker (non-pharmacist) level factors that may lead to the inappropriate dispensing of antibiotics were identified in this study. There is a dire need for the 
training of pharmacy workers and supervision of their dispensing practices. Strict enforcement of legislation is required to restrict the irrational use of antibiotics in Pakistan.

26 Key Words: Antibiotics, pharmacy workers, dispensing, inappropriate, community pharmacy,

27 education, health education

28

29

30

31

32

33

34

35

36

37

38

39

40

41

42 


\section{Introduction}

Dispensing of antibiotics without a prescription is a common practice in low and middle income countries (LMICs). ${ }^{1,2}$ According to the World Health Organization (WHO), there are 0.97 physicians per 1000 people in Pakistan, compared with 0.70 in India, 1.6 in China and 2.56 in the United States (US). ${ }^{3}$ Due to limited access to physicians, pharmacies are often the first port of call for the management of common ailments such as cough, cold, flu and infections. ${ }^{4-6}$ Low physician to patient ratio restricts the strict enforcement of regulations for over-the-counter (OTC) dispensing of antibiotics because the enforcement may limit the availability of antibiotics for patients who cannot see the physician at the time of illness. ${ }^{1}$ This exacerbates the inappropriate use of antibiotics, which is further complicated by the wide variability in the training of pharmacy workers. ${ }^{1,7}$

Absence of pharmacists at community pharmacies is common in developing countries such as India, Bangladesh, China and Kenya, where community pharmacies are operated by non-qualified and untrained pharmacy workers. ${ }^{1,8-11}$ Lack of qualification and training of pharmacy workers may lead to the inappropriate dispensing of medication, which is especially dangerous in the case of antibiotics. ${ }^{2}$ Inappropriate dispensing of antibiotics increases the risk of adverse outcomes, ${ }^{12}$ consequently compromising the desired therapeutic outcomes, safety of therapy, costs of treatment, increased morbidity and mortality rates, and antibiotic resistance. ${ }^{1,13}$ In 2018, the Centers for Disease Control and Prevention (CDC) reported that 23,000 deaths were caused by antibiotic resistance annually in the US, ${ }^{14}$ and this mortality rate is much higher in developing countries. ${ }^{15}$ Restricting the current increase in antibiotic resistance is an utmost priority of the WHO. ${ }^{16}$

Pakistan is ranked the third highest consumer of antibiotics (after India and China) among the 76 LMICs. ${ }^{17}$ Moreover, there is surge of antibiotic resistance in Pakistan, ${ }^{18}$ which 
67 is making antimicrobial therapy more complex for infectious diseases, for example, tuberculosis, malaria and typhoid fever. ${ }^{15}$ Several factors may be responsible for the inappropriate dispensing of antibiotics, including poor enforcement of health regulations, customer demands, overburdened healthcare system and inappropriate prescribing and dispensing practices. ${ }^{19}$ With regard to the dispensing of medicines at drug stores in Pakistan, the majority of the pharmacy workers have minimal formal education with 10 to 12 years of schooling and with little or no professional training in pharmacy/medical field ${ }^{20}$ Although the Pharmacy Act 1967 of Pakistan directs the proprietors of pharmacies to ensure the presence of a pharmacist at their premises, this rule is weakly implemented..$^{21}$ As a result, most of the pharmacies operate without the presence of a pharmacist, ${ }^{20}$ who is an appropriate healthcare professional to understand the pharmaceutical care needs of patients. A pharmacist also contributes significantly to the rational use of antibiotics by educating pharmacy workers and patients. $^{11,22}$

Pharmacy workers (non-pharmacist), in the absence of any supervision, dispense medicines to the patients attending pharmacies with or without prescriptions. ${ }^{20}$ Most often, patients also seek health advice from them for the treatment of minor ailments. ${ }^{15}$ This is alarming because such untrained staff risk the lives of people by promoting the irrational use of medicines, especially antibiotics. ${ }^{1,20}$ Previous studies from Pakistan have mainly focused on antibiotic use in hospital and clinic settings. ${ }^{23,24}$ The studies from the community pharmacy setting have explored the role of the pharmacist in this setting. ${ }^{15,25}$ Only a few studies reported the quality of pharmacy practices and overall dispensing patterns (not specifically focusing on antibiotics) of medicines by pharmacy workers, but the studies focusing on pharmacy workers with regard to their antibiotic dispensing practices are lacking. ${ }^{25,} 26$ Only a single study conducted by Imtiaz et al. reported the antibiotic dispensing practices in Pakistan but did not report the factors associated with the inappropriate dispensing of antibiotics. ${ }^{27}$ Therefore, this 

among pharmacy workers in Bahawalpur, Pakistan.

94

95

96

97

98

99

100

101

102

103

104

105

106

107

108

109

110 


\section{Study design}

A qualitative study design was adopted in which pharmacy workers (non-pharmacist) were interviewed face-to-face using a semi-structured interview schema. The respondents who were willing to participate in the study, aged $\geq 18$ years and with a minimum work experience of one year in a community pharmacy setting were recruited as study participants. In addition, only those pharmacy workers who admitted to the non-prescription dispensing of antibiotics and had attended a minimum of eight years of schooling were included in the study.

\section{Study setting}

The data were collected from the pharmacies located in Bahawalpur, a district of the Punjab province of Pakistan. According to the Primary \& Secondary Health Care Department of Bahawalpur, there are about 365 drug retail outlets located in various areas of Bahawalpur. Out of these, only a few pharmacies render the services of a community pharmacist. ${ }^{15,28}$ Most of these drug sale points were clustered around the Bahawal Victoria Hospital (BVH), which is a large tertiary care hospital. Others were located near crowded residential areas.

\section{Study tool}

The interview schema (Additional File 1) was developed after a comprehensive literature review and was designed to answer the research problem and address gaps in the existing literature. ${ }^{1,8,20}$ Before conducting the interviews, piloting of the interview schema was done among two pharmacy workers (non-pharmacist) to test the interview protocols and to confirm the uniformity, face validity and understandability of the interview guide. The pilot interviews were not included in the final analysis.

\section{Data collection}



was adopted for recruiting the study participants. ${ }^{15}$ In the first step, the pharmacies located within an approximately 500 metre radius of the BVH were shortlisted. This yielded 34 pharmacies. These pharmacies were then visited one by one (in predefined random order), and the consented participants were interviewed (by SA and IM) using the semi-structured interview schema. The interviews were conducted at the participants' workplaces or any other place convenient to them. A maximum of two participants were selected per pharmacy. The sample size was limited by applying the saturation point criteria. ${ }^{29}$ Data collection was stopped when no new theme/codes emerged. ${ }^{29}$ However, two more interviews were conducted to confirm that the saturation had been achieved. Before conducting the interviews, the study objectives were explained to the participants and consent to join the study was obtained. The interviews were conducted in Urdu, and all the interviews were audio recorded and observation notes were also taken. The participants were offered to listen to the recorded interviews.

\section{Data analysis}

The inductive thematic analysis approach (involving six phases: familiarization with the data, generation of initial codes, searching for themes, reviewing themes, defining and naming themes and producing the report) was used to analyse the data ${ }^{30}$ To become familiarized with the data, the audio recordings were transcribed verbatim and translated into English by SA. Relevant words, phrases and sentences indicating the study objectives were labelled and relevant codes were assigned to them. This step was undertaken by SA and IM. The coded data were then reduced and organized to draw final themes and subthemes by IMU, SA and IM. ${ }^{15}$ The drawn themes and conclusions were studied again and again to confirm that they reflected the aims of the study. Cross checking of the emergent themes and conclusion was undertaken by MA and discussed with the research team to confirm the aims of the study 

and to ensure data credibility. In the case of any conflict or disagreement, the final verdict was given by senior authors (IMU and MA).

Ethical approval

The conduct of the study was approved by the Pharmacy Research Ethics Committee (PREC) at the Islamia University Bahawalpur (Reference: 41/S-2018-/PREC, dated 31 May, 2018) and permission to conduct research was obtained from the Drug Controller of Bahawalpur. The study objectives were explained to the target participants before the interviews. Verbal consent to participate in the study and to audio record the interviews was obtained from the consented participants, and the consent was audio recorded. The participants were assigned identifier numbers (e.g., Respondent A, Respondent B, etc.) and the recordings were saved in a password protected computer. The participants were given the right to skip any questions or withdraw from the study without any further questions.

\section{Results}


of sixteen interviews were conducted. All participants were male with an average of 6.1 years

$181(\mathrm{SD}=3.1)$ of work experience. The age of the respondents ranged from 22 to 32 years (mean age $=26 ; \mathrm{SD}=3.2$ ). The duration of the interviews ranged from 25 to 41 minutes (mean duration $=31 ; \mathrm{SD}=5$ ). The demographic characteristics of the study participants are provided in Table 1.

Table 1: Demographic characteristics of participants

\begin{tabular}{|c|c|c|c|}
\hline Respondent & $\begin{array}{c}\text { Age } \\
\text { (years) }\end{array}$ & $\begin{array}{c}\text { Experience } \\
\text { (years) }\end{array}$ & $\begin{array}{c}\text { Interview } \\
\text { duration } \\
\text { (minutes) }\end{array}$ \\
\hline Respondent A & 27 & 8 & 25 \\
\hline Respondent B & 23 & 5 & 26 \\
\hline Respondent C & 24 & 8 & 38 \\
\hline Respondent D & 29 & 3 & 28 \\
\hline Respondent E & 30 & 4 & 34 \\
\hline Respondent F & 24 & 10 & 29 \\
\hline Respondent G & 22 & 1 & 31 \\
\hline Respondent H & 25 & 9 & 26 \\
\hline Respondent I & 23 & 8 & 29 \\
\hline Respondent J & 28 & 10 & 41 \\
\hline Respondent K & 24 & 3 & 29 \\
\hline Respondent L & 29 & 7 & 37 \\
\hline Respondent M & 32 & 11 & 28 \\
\hline Respondent N & 24 & 3 & 31 minutes (5) \\
\hline Respondent O & 25 & 6 & \\
\hline Respondent P & 31 & 6 years (3.1) & \\
\hline Mean (SD) & 26 years (3.2) & & 25 \\
\hline
\end{tabular}

Inductive thematic analysis of the data yielded four themes and 18 subthemes. The themes included knowledge about antibiotics, current antibiotic dispensing practices, reasons

189 for inappropriate dispensing and suggestions to limit the inappropriate dispensing of antibiotics. Exemplar quotations describing these themes and subthemes are provided in Table 

to restrict this practice; themes, subthemes and exemplar quotations

\begin{tabular}{|c|c|}
\hline Subthemes & Illustrative quotation \\
\hline \multicolumn{2}{|r|}{ Theme 1: Knowledge about antibiotics } \\
\hline \multirow[t]{3}{*}{ Familiarity with the terms } & $\begin{array}{l}\text { "Yes, I heard the term antibiotics these are medicines used to } \\
\text { treat many infections" (Respondent E) }\end{array}$ \\
\hline & $\begin{array}{l}\text { "No, I don't know the word irrational. I heard it } 1^{\text {st }} \text { time" } \\
\text { (Respondent B) }\end{array}$ \\
\hline & $\begin{array}{l}\text { "Antibiotic resistance is a new thing for me. Sorry I am not } \\
\text { familiar with that word. May be this includes the side effects of } \\
\text { antibiotics." (Respondent K) }\end{array}$ \\
\hline $\begin{array}{l}\text { Conditions to be treated with } \\
\text { antibiotics }\end{array}$ & $\begin{array}{l}\text { "No, I do not know whether this problem is bacterial or viral. I } \\
\text { just know that infections are treated with antibiotics." } \\
\text { (Respondent } \mathrm{H})\end{array}$ \\
\hline \multirow[t]{2}{*}{ Source of information } & $\begin{array}{l}\text { "During training the medicines written on the prescription which } \\
\text { comes at the pharmacy, we ask about the condition of the patient } \\
\text { that what the matter was. When they tell their problem, then we } \\
\text { come to know that this antibiotic is for that problem. Seniors also } \\
\text { guide. We also learnt in this way. Experience matters a lot in } \\
\text { this." (Respondent L) }\end{array}$ \\
\hline & $\begin{array}{l}\text { "Better solution is to read the leaflet. If it is not understandable } \\
\text { still then we take guidance from seniors or we take help from } \\
\text { internet." (Respondent } \mathrm{E})\end{array}$ \\
\hline \multicolumn{2}{|c|}{ Theme 2: Current antibiotic dispensing practices } \\
\hline $\begin{array}{l}\text { Common ailments treated at } \\
\text { pharmacy }\end{array}$ & $\begin{array}{l}\text { "People do not come with major problems. Generally they come } \\
\text { to us with minor ailments as flu, cough, throat infection or skin } \\
\text { infections. Then for these minor ailments we treat them." } \\
\text { (Respondent F) }\end{array}$ \\
\hline $\begin{array}{l}\text { Common antibiotics dispensed } \\
\text { without a prescription }\end{array}$ & $\begin{array}{l}\text { "In minor ailments we give ciprofloxacin, levofloxacin, } \\
\text { erythromycin, Augmentin, amoxiclav and cefixime." } \\
\text { (Respondent I) }\end{array}$ \\
\hline \multirow[t]{3}{*}{$\begin{array}{l}\text { Patterns of antibiotics } \\
\text { dispensing }\end{array}$} & $\begin{array}{l}\text { "For minor chest infections, cough or sputum, for these we give } \\
\text { antibiotics. We give for 1-2 days only, not for more than that." } \\
\text { (Respondent A) }\end{array}$ \\
\hline & $\begin{array}{l}\text { "Majority of the people ask for antibiotics without prescription. } \\
\text { Some people ask by name, some tell the symptoms. No system is } \\
\text { present here to restrict OTC purchase of antibiotics as for } \\
\text { narcotics there is a restriction on without a prescription sale. For } \\
\text { antibiotics, prescription only medicine is written on label but no } \\
\text { restriction is present on without a prescription sale. If same rules } \\
\text { as for narcotics would be present for the antibiotics and sale } \\
\text { register for the antibiotic is to be maintained, then I don't think } \\
\text { that these will be given without a prescription then." } \\
\text { (Respondent E) }\end{array}$ \\
\hline & $\begin{array}{l}\text { "People ask for 1-2 doses. As they ask for } 2 \text { doses of Augmentin. } \\
\text { Reasons to purchase } 1 \text { or } 2 \text { doses may include the patient cannot } \\
\text { afford the medicine even they are purchasing with coins because } \\
\text { they need medicines and do not have enough money." } \\
\text { (Respondent C) }\end{array}$ \\
\hline
\end{tabular}




\begin{tabular}{|c|c|}
\hline & $\begin{array}{l}\text { "It was told to the patients that for how many times you have to } \\
\text { take these medicines but side effects and other information } \\
\text { regarding the antibiotics are not generally provided to the } \\
\text { patients." (Respondent L) }\end{array}$ \\
\hline \multicolumn{2}{|c|}{ Theme 3: Reasons for inappropriate dispensing of antibiotics } \\
\hline $\begin{array}{l}\text { Knowledge about training } \\
\text { programs and current training } \\
\text { practices }\end{array}$ & $\begin{array}{l}\text { "Two types of training systems are present in the country, but } \\
\text { people do not know about these. Dispenser courses are offered } \\
\text { by different institutions and pharmacy technician courses are } \\
\text { also available. But here in Pakistan no trend because you can } \\
\text { avail jobs without such courses easily". (Respondent M) }\end{array}$ \\
\hline & $\begin{array}{l}\text { "No training is required for the pharmacy worker job. On job we } \\
\text { learn how to read prescriptions and about medicines from our } \\
\text { seniors. As seniors are also not professionals so lack of } \\
\text { professionalism results in inappropriate dispensing of } \\
\text { medicines". (Respondent C) }\end{array}$ \\
\hline Business point of view & $\begin{array}{l}\text { "It should not be given, but for } 80-90 \% \text { we dispense. Although it, } \\
\text { is not right, but we give to increase our sales and to earn money." } \\
\text { (Respondent C) }\end{array}$ \\
\hline Social acceptance & $\begin{array}{l}\text { "As I told you earlier that people do not have money so somebody } \\
\text { has to care them. If they do not have time to visit doctor then also } \\
\text { we have to provide them their basic medicine requirements..." } \\
\text { (Respondent E) }\end{array}$ \\
\hline False feeling of being qualified & $\begin{array}{l}\text { "We are satisfied that we are qualified for giving that medicine. } \\
\text { We know one thing. We have learnt it with our experience. We } \\
\text { have much experience." (Respondent } \mathrm{O} \text { ) }\end{array}$ \\
\hline $\begin{array}{l}\text { Pressurized by customers and } \\
\text { owner }\end{array}$ & $\begin{array}{l}\text { "Sometimes people start forcing. We are also pressurized by the } \\
\text { owner of a pharmacy. If we refuse, customers go to another } \\
\text { pharmacy and get medicine from there. It causes us business } \\
\text { loss." (Respondent D) }\end{array}$ \\
\hline $\begin{array}{l}\text { Lack of healthcare facilities in } \\
\text { public sector clinics }\end{array}$ & $\begin{array}{l}\text { "The main reason is the behaviour of doctors with their patients. } \\
\text { Doctors don't attend them as they should be attended. I am } \\
\text { talking about government sector. Mostly people go to the } \\
\text { government sector because } 70 \% \text { of our population cannot afford } \\
\text { private services. Therefore, they go to government hospitals and } \\
\text { there the behaviour of doctors is not good so they direct come to } \\
\text { the pharmacies. The reason for the doctor's behaviour is their } \\
\text { private practice. They check well at private clinics. Timing issues } \\
\text { also exist." (Respondent B) }\end{array}$ \\
\hline $\begin{array}{l}\text { High consultation fees of } \\
\text { doctors }\end{array}$ & $\begin{array}{l}\text { "They come to the pharmacy directly. They do not go to the } \\
\text { doctor because here they can get medicine in } 20 \text { rupees but if they } \\
\text { go to the doctor, } 1000 \text { rupees fees will be paid there and the } \\
\text { doctor will write expensive tests and then expense of medicine is } \\
\text { also there..." (Respondent } \mathrm{J} \text { ) }\end{array}$ \\
\hline High cost of antibiotics & $\begin{array}{l}\text { "Antibiotics cost more than the other medicines leading to the } \\
\text { inconvenience of patients. Therefore majority of the patients } \\
\text { demand less than the full course of therapy. Sometimes some } \\
\text { habitual people tended to take less than the full course as they } \\
\text { wanted to check whether the medicine is effective or not." } \\
\text { (Respondent E) }\end{array}$ \\
\hline $\begin{array}{l}\text { Restricted timing of the } \\
\text { outdoor department (outpatient } \\
\text { clinics) at public sector } \\
\text { hospitals }\end{array}$ & $\begin{array}{l}\text { "In government hospitals there is a specific time, mostly up to } 2 \\
\text { o'clock. If in evening time anyone gets any problem so there is } \\
\text { no facility like this. So they go to the medical store. Pharmacy }\end{array}$ \\
\hline
\end{tabular}




\begin{tabular}{|l|l|}
\hline \multicolumn{2}{|c|}{ Theme 4: Suggestions to limit the inappropriate dispensing of antibiotics } \\
their knowledge..." (Respondent O)
\end{tabular}

All respondents were well aware of the term "antibiotics", however, they were ignorant about the conditions that are treated with antibiotics. According to the respondents, antibiotics could be given for all infections, whether bacterial or viral. They were unable to distinguish between bacterial and viral infections. "Antibiotic resistance" was a new term for the majority of the pharmacy workers. Only two respondents had heard the term "antibiotic resistance", however, they were considering the adverse effects of antibiotics as antibiotic resistance. The knowledge of all respondents about antibiotics was experience based. They had memorized the prescriptions provided by doctors and dispensed the same medications to other patients with 
similar symptoms. Sometimes, medical sales representatives and pharmacists also educated them about the use of medicines. The respondents said that when they did not know the answer to any question, they referred the patient to a pharmacist or someone senior. Sometimes, literature provided in the patient information leaflets was also a source of information for them.

\section{Theme 2: Current antibiotic dispensing practices}

According to the respondents, patients suffering from mild illness visited the pharmacy instead of visiting a doctor. The most common symptoms for which people visited a pharmacy were sore throat or respiratory tract infections, injury or wound, diarrhoea, fever, flu and cough. All respondents routinely dispensed antibiotics without a prescription in these conditions. Mostly they dispensed antibiotics for 1-2 days only. If the patient did not recover from the illness, they referred them to a doctor. The antibiotics that were most commonly dispensed without a prescription, are listed in Table 3.

Table 3: Most commonly dispensed antibiotics without a prescription

\begin{tabular}{|l|l|}
\hline \multicolumn{1}{|c|}{ Ailment } & \multicolumn{1}{|c|}{ Antibiotics used by the participants } \\
\hline Throat infections & $\begin{array}{l}\text { Levofloxacin, Co-amoxiclav, Azithromycin, } \\
\text { Erythromycin, Moxifloxacin, Lincomycin }\end{array}$ \\
\hline Fever & Ciprofloxacin, Cefixime, Co-amoxiclav \\
\hline Wounds & Cephradine, Co-amoxiclav \\
\hline Tooth infections & Doxycycline, Metronidazole \\
\hline
\end{tabular}

According to the respondents, the majority of patients visiting pharmacies for the purchase of antibiotics (without a prescription) demanded the medicines by name; however, some patients asked the pharmacy workers to suggest a medicine by telling them the signs and 
symptoms of their disease. While dispensing antibiotics without a prescription, the patients were counselled on how and when to take the antibiotics. However, side effects and precautionary measures were not reviewed, as pharmacy workers were unaware of these.

\section{Theme 3: Reasons for inappropriate dispensing of antibiotics}

Training of pharmacy workers was the first emergent reason for the inappropriate dispensing of antibiotics. The majority of participants were not familiar with the existing training courses being offered in the country. Only two pharmacy workers were aware of the training programmes. Almost all of them were trained in their workplace by their seniors. The majority of respondents stated that they dispensed antibiotics without a prescription because of the culture of not refusing customers asking for any type of medicine. The respondents related the non-prescription sale of antibiotics from a business point of view. According to them, they wanted to improve the pharmacy's income by increasing the sale of medicines. Another reason for the inappropriate dispensing of antibiotics was the financial condition of the patients who could not pay the consultation fees of doctors at private clinics. According to them, patients were reluctant to go to the public sector hospitals because of the rude behaviour of doctors, long waiting times and lack of facilities. According to the respondents, people who could not afford the fees of private clinics came directly to the pharmacy for their health problems. In such a case, it was their responsibility to dispense medicines (without a prescription). The respondents stated that the dispensing of antibiotics without a prescription was right, as they knew about the medicines based on their experience. They said that they felt qualified to give medicines for minor ailments on the basis of their experience. Sometimes, pharmacy workers were also pressured by owners and customers to dispense antibiotics without a prescription.

All respondents stated that they dispensed less than a full course of therapy. For this, various reasons were mentioned and one of these was the high cost of antibiotics. Moreover, it 
was reported that some people tended to take less than the full course of antibiotics, as they wanted to check if an antibiotic was effective for them by taking 1-2 doses.

\section{Theme 4: Suggestions to limit the inappropriate dispensing of antibiotics}

According to the respondents, antibiotics should not be dispensed without a prescription, and the patients should be educated about the appropriate use of antibiotics. They said that they cannot force the patients to visit the doctor or to take the full course of antibiotics. They further said that it was necessary to make the general public aware about the hazards of antibiotic overuse and misuse. They further emphasized that the consultation fees of doctors should be reduced and rude behaviour of doctors should be changed in the public sector hospitals.

The respondents suggested that the training of pharmacy workers should be necessary for this job. The government should organize the training programmes for workers (nonpharmacist dispensers). According to the study participants, the government should take necessary measures to stop the non-prescription sale of antibiotics. The respondents further suggested that the opening hours of public sector outdoor clinics (outpatient clinics) should be increased. Consequently the poor patients could consult doctors free of charge. 
267 for the inappropriate dispensing of antibiotics among pharmacy workers. The findings revealed that antibiotics were dispensed inappropriately by the pharmacy workers for various reasons. The majority of workers had inadequate knowledge about the conditions to be treated with antibiotics, thus playing the foremost role in disseminating antibiotic misuse and aggravating antibiotic resistance. Two types of training courses (pharmacy technician courses and certified diplomas for drug dispensing) were being offered to pharmacy workers in the country ${ }^{20,31}$; however, the majority of the respondents were unaware of the existence of these programmes. Previous studies conducted in Pakistan have shown similar findings that pharmacies are largely run by non-qualified and untrained dispensers..$^{20,26}$ It was interesting to note that the respondents were eager to learn more about the medicines and to attend the pharmacy training courses. This might be due to the fact that they perceive training as an opportunity for improved job status in terms of better salaries rather than a desire to better serve the public. Moreover, all respondents in the study were male. This might be due to the social and cultural barriers in Pakistan where female staff is not encouraged to work where direct interaction with the community occurs. Conversely, this may not be the case in other countries, where females also serve at pharmacies. $^{32,33}$

All participants were well aware of the term "antibiotics", but they did not know the conditions for which antibiotics could be used. There was frequent dispensing of antibiotics for viral problems, such as flu, cough and cold, for which these are not effective. Comparable results were shown in previous studies conducted in Greece and Thailand, indicating more than a $70 \%$ purchase rate of antibiotics for viral infections. ${ }^{34,35}$ Similarly, a study from Pakistan revealed that antibiotics were widely misused for cold, cough, flu, fever, and sore throat. ${ }^{36}$ The reason could be the lack of knowledge of workers about infectious agents. Furthermore, workers were not well trained to distinguish between bacterial and viral infections, and they 
assumed that antibiotics work in all types of infections. All interviewed employees in this study were unaware of the causes of antibiotic resistance. They considered the adverse effects of antibiotics as antibiotic resistance. This finding highlights the apprehensions in the quality of pharmacy worker training in Pakistan. The training system for pharmacy workers should be considered compulsory, for example, in the UK, training is mandatory for the registration of pharmacy technicians. ${ }^{37}$ A comprehensive pharmacy technician register is maintained in the UK, and all pharmacy technicians licensed to practice at community pharmacies must renew their registration annually with the General Pharmaceutical Council. ${ }^{38}$

According to the Drugs Act 1967 of Pakistan, antibiotics are not over-the-counter (OTC) medicines and should be dispensed only with medical prescriptions. ${ }^{21}$ However, contrary to this, all participants of this study reported OTC dispensing of antibiotics especially to those patients who had financial problems and could not pay the consultation fees of doctors. The previous studies conducted in Pakistan, Egypt, Spain and Nepal also reported 60\%, 76\%, $54 \%$ and $59 \%$ non-prescription dispensing of antibiotics, respectively. ${ }^{39-42}$ These findings show that, in developing countries such as Pakistan, low income, fewer resources and less healthcare facilities compel people to the inexpensive attainment of healthcare services. ${ }^{43,}{ }^{44}$ In Pakistan, lied in the range of Rs. 75-150 Pakistani Rupees (pkr) per day, while with regard to the nonprescription purchase of antibiotics, almost $41 \%$ of bills costed less than Rs. 75 pkr per day. ${ }^{27}$

The study participants frequently dispensed short courses of antibiotics, and this practice can be related to the pharmacy worker's knowledge of antibiotics and the patient's economic status. On the other hand, our study participants reported the high prices of antibiotics as one of the main factors associated with the shortened courses of antibiotics. 
Indeed, the participants considered dispensing of a shortened course of antibiotic as a charitable

317 action. They dispensed 1-2 doses of antibiotics according to the patient's economic status, possibly because they were unaware of the hazards of incomplete courses. Barker et al. reported similar findings from India, as $85 \%$ of pharmacy workers sold shortened antibiotic courses, often just for 1-2 days. ${ }^{1}$ According to the respondents, customers visiting a pharmacy (without a prescription) asked for the specific antibiotics by name, and most of the times, pharmacy staff was forced by the patients to provide them antibiotics without a prescription. A study conducted in India showed that $63 \%$ of customers asked for antibiotics directly by name. ${ }^{45}$ Although patients often do not have correct knowledge about antibiotics, they influence dispensing practices by demanding antibiotics based on their previous experience or suggestions by friends or relatives. ${ }^{5}$ Limited access to healthcare facilities could be an influential trigger for selfmedication with antibiotics and the inappropriate dispensing of antibiotics by pharmacy workers. A survey reported that only $45 \%$ of Pakistanis had access to a physician and adequate healthcare facilities and only $21 \%$ of the population had access to public sector healthcare facilities. ${ }^{36}$ In this scenario, pharmacy workers thought of themselves as morally responsible for providing antibiotics without a prescription and even less than the recommended course to those who could not afford them. The study participants also reported financial gain and profit maximization as main factors attributable to the inappropriate dispensing of antibiotics in Pakistan. Similar findings were shown in a previous study conducted in Tanzania, where pharmacy workers stated financial gain as a motivating factor for providing medicines to the customers without a valid prescription. ${ }^{44}$ It may be due to the reason that, in developing countries, pharmacies are business places and pharmacy workers always look for opportunities to sell their medicines. ${ }^{44}$

Comprehensive instructions about medicines consist of information about their use as well as possible side effects, drug interactions, precautions, etc. Disappointingly, according to 
the findings of this study, patients were only educated about the frequency of antibiotic use.

342 They were not educated about the potential side effects of the medicines and other precautionary measures, for example, whether the antibiotic was to be taken with or without food, storage conditions, special warnings, etc. ${ }^{2,8,9}$ Several reasons might be responsible for the provision of limited medicine-related information to patients. Lack of medicine-related knowledge of the pharmacy workers, little or no interest in the patient's health, lack of time and absence of pharmacists at drug retail outlets are possible reasons, to name a few. ${ }^{46}$ Our study participants obtained medicine-related information from their seniors, patient information leaflets and the Internet, and this finding is in accordance with the findings of a Nigerian study. ${ }^{47}$ Interpretation of medical literature by non-pharmacist pharmacy workers without basic medical education may be misleading and can negatively influence the health of patients. Interestingly, with this poor state of knowledge about antibiotics, the majority of our study participants (non-pharmacist pharmacy workers) alleged that they were capable of meeting their professional responsibilities based on having ample experience in the field. This misperception is alarming and needs the urgent attention of healthcare authorities.

This study has a few limitations. First, a convenience sampling technique was used to recruit the study participants. Random sampling was not possible, because some of the pharmacy workers were hesitant to participate in the study due to lack of their medicine-related knowledge. There were also some restrictions from the pharmacy owners to share data about the dispensing practices at their pharmacies. Second, the findings of this study cannot be generalized to the whole of Pakistan, because the data were collected from one city (i.e., Bahawalpur). However, the findings provide an insight of what is happening in the country based on the fact that a uniform healthcare policy is implemented throughout Pakistan, and the antibiotic dispensing practices could be similar throughout the country. Third, the perceptions of patients and pharmacy owners about the use and dispensing of antibiotics were not captured. 
This should be addressed in future studies. Furthermore, longitudinal studies must be conducted in the future to find the change in antibiotic dispensing practices over time.

\section{Impact of findings on policy and practice}

Besides the implication of this study to literature, there are some consideration for policy and practice. The findings warrant the attention of the government, who may need to immediately enforce legislation to restrict the sale of antibiotics without a prescription. Similarly, the availability of pharmacists must be assured at pharmacies, who can not only supervise the pharmacy workers while dispensing antibiotics but also educate patients or their caregivers about the appropriate use of antibiotics. On a long-term basis, training, supervision and involvement of pharmacy workers in patient healthcare are necessary to promote the rational use of antibiotics. There is a need to put into legislation that only formally trained personnel should be allowed to dispense medicines at drug retail outlets. To tackle the compelling patients, health campaigns and seminars can be organized to spread awareness among the general public. Harms of the inappropriate use of antibiotics should be explained to patients by healthcare providers (doctors and pharmacists) and well-trained pharmacy staff.

\section{Conclusion}

Under-dispensing and dispensing of antibiotics without a need were reported in this study. Lack of knowledge of pharmacy workers, customer's demands, false feelings of being qualified, social acceptance, public beliefs, high consultation fees of doctors, expensive diagnostic tests, economic influences and profit maximization were the main factors associated with the inappropriate dispensing of antibiotics. The perceptions to provide care to all patients and the dispenser's limited understanding of antibiotic resistance were also contributing factors. 
390 Not declared.

$391 \quad$ Funding

392 This research did not receive any specific grant from funding agencies in the public, 393 commercial, or not-for-profit sectors.

\section{Acknowledgement}

395 We would like to thank the respondents for their participation.

396

397

398

399

400

401

402

403

404

405

406

\section{Reference}

407

1. Barker, A.K., et al., What drives inappropriate antibiotic dispensing? A mixed-methods study

of pharmacy employee perspectives in Haryana, India. BMJ open, 2017. 7(3): p. e013190.

2. Peković, V.M., et al., Initiatives to reduce non-prescription sales and dispensing of antibiotics in the Republic of Srpska; findings and implications. 
3. The World Bank. Physicians (per 1,000people). 2012; Available from: https://data.worldbank.org/indicator/SH.MED.PHYS.ZS?end=2012\&locations=CH.

4. Ansari, M., Evaluation of community pharmacies regarding dispensing practices of antibiotics in two districts of central Nepal. PloS one, 2017. 12(9): p. e0183907.

5. Atif, M., et al., What drives inappropriate use of antibiotics? A mixed methods study from Bahawalpur, Pakistan. Infection and drug resistance, 2019. 12: p. 687.

6. Atif, M., et al., Pharmaceutical policy in Pakistan, in Pharmaceutical Policy in Countries with Developing Healthcare Systems. 2017, Springer. p. 25-44.

7. Miller, R. and C. Goodman, Performance of retail pharmacies in low-and middle-income Asian settings: a systematic review. Health policy and planning, 2016. 31(7): p. 940-953.

8. Chang, J., et al., Sale of antibiotics without a prescription at community pharmacies in urban China: a multicentre cross-sectional survey. Journal of Antimicrobial Chemotherapy, 2017. 72(4): p. 1235-1242.

9. Kwena, Z., et al., Provider characteristics among staff providing care to sexually transmitted infection self-medicating patients in retail pharmacies in Kibera slum, Nairobi, Kenya. Sexually transmitted diseases, 2008. 35(5): p. 480-483.

10. Saha, S. and M.T. Hossain, Evaluation of medicines dispensing pattern of private pharmacies in Rajshahi, Bangladesh. BMC health services research, 2017. 17(1): p. 136.

11. Sakeena, M., A.A. Bennett, and A.J. McLachlan, Enhancing pharmacists' role in developing countries to overcome the challenge of antimicrobial resistance: a narrative review. Antimicrobial Resistance \& Infection Control, 2018. 7(1): p. 63.

12. Courtenay, M., D. Gillespie, and R. Lim, Patterns of dispensed non-medical prescriber prescriptions for antibiotics in primary care across England: a retrospective analysis. Journal of Antimicrobial Chemotherapy, 2017. 72(10): p. 2915-2920.

13. Radyowijati, A. and H. Haak, Improving antibiotic use in low-income countries: an overview of evidence on determinants. Social science \& medicine, 2003. 57(4): p. 733-744.

14. Fleming-Dutra, K.E., et al., Be antibiotics aware: smart use, best care. 2018.

15. Sarwar, M.R., et al., Knowledge of community pharmacists about antibiotics, and their perceptions and practices regarding antimicrobial stewardship: a cross-sectional study in Punjab, Pakistan. Infection and drug resistance, 2018. 11: p. 133.

16. Organization, W.H., Global antimicrobial resistance surveillance system (GLASS) report: early implementation 2016-2017, in Global antimicrobial resistance surveillance system (GLASS) report: early implementation 2016-2017. 2017.

17. Gulf news. Sharp rise in antibiotic use in Pakistan. 2018; Available from: https://gulfnews.com/.../pakistan/sharp-rise-in-antibiotic-use-in-pakistan--study-1.220.

18. Kumarasamy, K.K., et al., Emergence of a new antibiotic resistance mechanism in India, Pakistan, and the UK: a molecular, biological, and epidemiological study. The Lancet infectious diseases, 2010. 10(9): p. 597-602.

19. Sakeena, M., A.A. Bennett, and A.J. McLachlan, Non-prescription sales of antimicrobial agents at community pharmacies in developing countries: a systematic review. International journal of antimicrobial agents, 2018.

20. Hussain, A. and M.I.M. Ibrahim, Qualification, knowledge and experience of dispensers working at community pharmacies in Pakistan. Pharmacy practice, 2011. 9(2): p. 93.

21. Pharmacy act, Pharmacy act 1967 - Pakistan Medical \& Dental Council. 1967.

22. Essack, S., J. Bell, and A. Shephard, Community pharmacists-Leaders for antibiotic stewardship in respiratory tract infection. Journal of clinical pharmacy and therapeutics, 2018. 43(2): p. 302-307.

23. Atif, M., et al., Assessment of WHO/INRUD core drug use indicators in two tertiary care hospitals of Bahawalpur, Punjab, Pakistan. Journal of pharmaceutical policy and practice, 2016. 9(1): p. 27. 
24. Atif, M., et al., Assessment of core drug use indicators using WHO/INRUD methodology at primary healthcare centers in Bahawalpur, Pakistan. BMC health services research, 2016. 16(1): p. 684.

25. Rabbani, F., et al., Behind the counter: pharmacies and dispensing patterns of pharmacy attendants in Karachi. JPMA: Journal of the Pakistan Medical Association, 2001. 51(4): p. 149.

26. Butt, Z.A., et al., Quality of pharmacies in Pakistan: a cross-sectional survey. International Journal for Quality in Health Care, 2005. 17(4): p. 307-313.

27. Imtiaz, F., et al., Antibiotic Dispensing \& Prescription Pattern in Pharmacies of Islamabad \& Rawalpindi: Pakistan. International Journal of Collaborative Research on Internal Medicine \& Public Health, 2017. 9(5): p. 683-692.

28. Atif, M., et al., Evaluation of prescription errors and prescribing indicators in the private practices in Bahawalpur, Pakistan. Journal of the Chinese Medical Association, 2018. 81(5): p. 444-449.

29. Saunders, B., et al., Saturation in qualitative research: exploring its conceptualization and operationalization. Quality \& quantity, 2018. 52(4): p. 1893-1907.

30. Braun, V. and V. Clarke, Using thematic analysis in psychology. Qualitative research in psychology, 2006. 3(2): p. 77-101.

31. Ali, I., et al., Self-medication and non-adherence with antibiotics: the current situation in Pakistan. Journal of Pharmacy Practice and Research, 2016. 46(1): p. 34-37.

32. Hansen, J. and J.H. Olsen, Cancer morbidity among Danish female pharmacy technicians. Scandinavian journal of work, environment \& health, 1994: p. 22-26.

33. Hawthorne, N. and C. Anderson, The global pharmacy workforce: a systematic review of the literature. Human resources for health, 2009. 7(1): p. 48.

34. Apisarnthanarak, A., et al., Nonjudicious dispensing of antibiotics by drug stores in Pratumthani, Thailand. Infection Control \& Hospital Epidemiology, 2008. 29(6): p. 572-575.

35. Contopoulos-loannidis, D.G., et al., Pathways for inappropriate dispensing of antibiotics for rhinosinusitis: a randomized trial. Clinical infectious diseases, 2001. 33(1): p. 76-82.

36. Aziz, M.M., et al., Pattern of medication selling and self-medication practices: A study from Punjab, Pakistan. PloS one, 2018. 13(3): p. e0194240.

37. Jee, S.D., E.I. Schafheutle, and P.R. Noyce, Exploring the process of professional socialisation and development during pharmacy pre-registration training in England. International Journal of Pharmacy Practice, 2016. 24(4): p. 283-293.

38. General Pharmaceutical Council. Registration and revalidation for pharmacists and pharmacy technicians in UK. 2019 [cited 201927 June]; Available from: https://www.pharmacyregulation.org/.

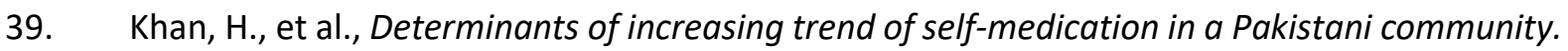
Tropical Journal of Pharmaceutical Research, 2014. 13(3): p. 437-443.

40. Javato-Laxer, M., E. Navarro, and R. Littana, Antimicrobial patterns in hospitals: determinants and proposed interventions. Philipp. J. Microbiol. Infect. Dis, 1989. 18: p. 41-46.

41. Sabry, N.A., S.F. Farid, and D.M. Dawoud, Antibiotic dispensing in Egyptian community pharmacies: an observational study. Research in Social and Administrative Pharmacy, 2014. 10(1): p. 168-184.

42. Guinovart, M.C., et al., Obtaining antibiotics without prescription in Spain in 2014: even easier now than 6 years ago. Journal of Antimicrobial Chemotherapy, 2015. 70(4): p. 1270-1271.

43. Morgan, D.J., et al., Non-prescription antimicrobial use worldwide: a systematic review. The Lancet infectious diseases, 2011. 11(9): p. 692-701.

44. García, P.J., et al., Knowledge, attitudes and practices related to tuberculosis in pharmacy workers in a cross-sectional survey in El Agustino, Peru. PloS one, 2018. 13(7): p. e0196648.

45. Kamat, V.R. and M. Nichter, Pharmacies, self-medication and pharmaceutical marketing in Bombay, India. Social science \& medicine, 1998. 47(6): p. 779-794. 
511

512

513

514

515

516

517

46. Shet, A., S. Sundaresan, and B.C. Forsberg, Pharmacy-based dispensing of antimicrobial agents without prescription in India: appropriateness and cost burden in the private sector. Antimicrobial resistance and infection control, 2015. 4(1): p. 55.

47. Auta, A., et al., Medicine vendors: self-medication practices and medicine knowledge. North American journal of medical sciences, 2012. 4(1): p. 24. 